\title{
Incorporation of Radiolabelled Substrates into Mycobacteri- al Lipids of M. Bovis BCG and M. Kansasii
}

\author{
Nirmala Deo, Divakar Sharma, Deepa Bisht, Krishnamurthy Venkatesan*
}

Department of Biochemistry, National JALMA Institute for Leprosy and Other Mycobacterial Diseases, Tajganj, Agra, India

*Corresponding author: Krishnamurthy Venkatesan, Department of Biochemistry, National JALMA Institute for Leprosy and Other Mycobacterial Diseases, Tajganj, Agra 282004, India, Tel: 91-562-2331751/ Fax: 0562-2331755;

E-mail: drvenkatesan1952@gmail.com

\begin{abstract}
Background: Diseases caused by microorganisms of the genus Mycobacterium continue to be a serious problem. The cell envelope constitutes up to $60 \%$ of the dry weight of lipids. The cell wall of the mycobacterium is essential for their growth and survival in the infected host. The cell wall lipids have been isolated from $M$. bovis BCG and M. kansasii mycobacterial strains and studied the incorporation of radiolabelled substrates for exploring the potential involvement of lipid biosynthetic pathways.

Methods: We have incubated $M$. bovis, BCG and $M$. kansasii with radiolabelled substrates-1-C $\mathrm{C}^{14}$-palmitic acid, 1-C $\mathrm{C}^{14}$-sodium-n-valerate, 1-C $\mathrm{C}^{14}$-sodium-n-acetate and $1-\mathrm{C}^{14}$-sodium-n-propionate and calculated the incorporation in PGL, PDIM and mycolates by Liquid Scintillation Counter.

Results: We have found the percentage of assimilation of 1-C ${ }^{14}$-palmitic acid into lipids of $M$. bovis BCG and M. kansasii were PGL: 0.39\%, PDIM: 0.70\% \& Mycolates: $0.30 \%$ and PGL: $0.42 \%$, PDIM: $0.81 \%$ \& Mycolates: $1.45 \%$ respectively. The percentage of assimilation of 1-C ${ }^{14}$-sodium-n-valerate into lipids of $M$. bovis BCG and M. kansasii were PGL: 0.28\%, PDIM: 0.58\% \& Mycolates: $1.05 \%$ and PGL: 0.35\%, PDIM: $0.68 \%$ \& Mycolates: $0.90 \%$ respectively. The percentage of assimilation of 1-C $\mathrm{C}^{14}$ - sodium-n- acetate into lipids of $M$. bovis BCG and M. kansasii were PGL: $0.45 \%$, PDIM: $0.80 \%$ \& Mycolates: $1.45 \%$ and PGL: $0.48 \%$, PDIM: $0.90 \%$ \& Mycolates: $1.50 \%$ respectively. The percentage of assimilation of $1-\mathrm{C}^{14}$-sodium-npropionate into lipids of $M$. bovis BCG \& M. kansasii were PGL: 0.48\%, PDIM: 0.85\% \& Mycolates: $1.40 \%$ and PGL: 0.50\%, PDIM: $0.90 \%$ and Mycolates: $1.48 \%$ respectively.

Conclusion: The findings of this study suggest the usefulness of radiolabelled substrate incorporation approach for exploring the involvement of lipid biosynthetic pathway.
\end{abstract}

Received Date: January 31, 2017

Accepted Date: February 17, 2017

Published Date: February 27, 2017

Citation: Nirmala Deo., et al. Incorporation of Radiolabelled Substrates into Mycobacterial Lipids of M. Bovis BCG and M. Kansasii. (2017) J Anal Bioanal Sep Tech 2(1): 58- 62.

DOI: $10.15436 / 2476-1869.17 .1324$

Keywords: Phenolic glycolipid; Pthiocerol dimycocerosate; Mycolates; Mycobacteria; Palmitic acid; Sodium-n-valerate; Sodium-n- acetate; Sodium-n- propionate

Abbreviations: PGL: Phenolic glycolipids; PDIM: Phthiocerol dimycocerosates; cpm: counts per minute; TLC: Thin layer chromatography

\section{Introduction}

Mycobacteria synthesize a wide variety of complex lipids to maintain very unusual structures. Mycobacterial waxes are composed of mycocerosic acid diesters of three closely related diols: phthiocerol $\mathrm{A}$, phthiocerol $\mathrm{B}$, and phthiodiolone $\mathrm{A}^{[1-3]}$. Dimycocerosates were first characterized in M. tuberculosis and detected by infra-red spectroscopy in lipid extracts from M. tuberculosis, M. bovis ${ }^{[4]}, M$. marinum and M. leprae ${ }^{[5]}$. The presence of phthiocerol dimycocerosates was reported by Goren et $\mathrm{al}^{[6]}$ in virulent strains of $M$. tuberculosis but not attenuated strains.

There are only few studies on the uptake and incorporation of radiolabelled substrates into one or other specific cell wall lipid of mycobacteria grown in culture medium or macrophage/Schwannoma cell lines (with M. leprae) in vitro. The present study was designed to study the incorporation of the radiolabelled substrates, 1-C $\mathrm{C}^{14}$-palmitate, 1-C $\mathrm{C}^{14}$-valerate, 1-C $\mathrm{C}^{14}$-sodium-n- acetate and 1- $\mathrm{C}^{14}$-sodium-n- propionate into a host of cell wall lipid fractions- phenolic mycosides (PGLs), phthioce- 
rol based wax esters (PDIMs) and mycolates of $M$. bovis BCG and $M$. kansasii. The research gained from incorporation of radiolabelled substrates might help in exploring the potential involvement of lipid biosynthetic pathways to maintain the cell wall/rigidity of $M$. bovis BCG and $M$. kansasii. Further research in this direction might be used for studying the antimycobacterial efficacy of various drugs.

\section{Materials and Methods}

\section{Extraction of free non-polar lipids}

The extraction method involves the treatment of organisms with a biphasic mixture of methanolic saline and petroleum ether (b.p. $60-80^{\circ} \mathrm{C}$ ) as described by Dobson et al ${ }^{[3]}$. Harvested $M$. bovis $\mathrm{BCG} / M$. kansasii organisms were suspended in 3 $\mathrm{ml}$ of aqueous methanol in $8.5 \mathrm{ml}$ test tubes screw capped with PTFE (poly tetra flour ethylene) lined caps. Free non-polar lipids were extracted by partitioning between the organisms in aqueous methanol and $3 \mathrm{ml}$ of petroleum ether (b.p. $60-80^{\circ} \mathrm{C}$ ) for $15 \mathrm{~min}$. The mixture was centrifuged for $5 \mathrm{~min}$ at $2000 \mathrm{rpm}$ at room temperature. The upper petroleum ether layer were separated and stored in small screw capped vial. The lower layer was re-extracted with a further aliquot of $2 \mathrm{ml}$ petroleum ether for $15 \mathrm{~min}$. The combined petroleum ether extracts was evaporated to dryness under a stream of nitrogen at $37^{\circ} \mathrm{C}$ and examined for phenolic glycolipids and wax esters (phthiocerol dimycocerosates).

\section{TLC analysis of phenolic glycolipids extracted from cells}

The non-polar lipids extracted with petroleum ether was dissolved in a small volume of chloroform and spotted on the corner of a $10 \times 10 \mathrm{~cm}$ silica gel G-precoated aluminium plates and developed with chloroform-methanol $(96: 4, \mathrm{v} / \mathrm{v})$ once in the first direction followed by toluene-acetone $(80: 20, \mathrm{v} / \mathrm{v})$ thrice in the second direction. The plates were sprayed with $\alpha$-napthol-sulphuric acid reagent and heated at $120^{\circ} \mathrm{C}$ for $10 \mathrm{~min}$. The presence of PGL was confirmed by comparing the mobility of authentic mycoside available in the Department.

\section{TLC analysis of wax esters ( Phthiocerol Dimycocerosates -PDIMs)}

The other half of the non-polar lipid extract was deposited on Silica gel $\mathrm{G}$ - precoated plate $(10 \times 10 \mathrm{~cm}$, Merck) which was run in Petroleun Ether-Diethyl ether (90:10, v/v) for the detection of phthiocerol dimycocerosates (wax esters). The characteristic lipids were visualized by spraying plate with $\mathrm{H}_{2} \mathrm{SO}_{4}$, followed by heating.

\section{Mycolic acid extraction and preparation of methyl esters}

The aqueous portion containing cells left out after extraction of non-polar lipids was centrifuged and the supernatant was collected and saved for radioactive counting. The residual cell material was saponified to release cell-wall 'bound lipids' like mycolic acids by employing the procedure described by Dobson et $\mathrm{al}^{[3]}$. The material was subjected to alkaline methanolysis by treating with a mixture of methanol $(1 \mathrm{ml}), 30 \%$ aqueous $\mathrm{KOH}(1 \mathrm{ml})$ and toluene $(0.1 \mathrm{ml})$ and heating in an oven at $75^{\circ} \mathrm{C}$ for $18 \mathrm{hrs}$. The alkaline contents were cooled and acidified to $\mathrm{pH} 2.0$ with $6 \mathrm{~N} \mathrm{HCl}$ and extracted with diethyl ether $(3 \times 1 \mathrm{ml}$ aliquots). The combined extracts collected in an $8.5 \mathrm{ml}$ screw capped tube were evaporated to dryness under a stream of nitrogen at $37^{\circ} \mathrm{C}$. The dried lipid material supposedly containing mycolic acids was dissolved in $1 \mathrm{ml}$ of dichloromethane and treated with $1 \mathrm{ml}$ of catalyst solution and $0.5 \mathrm{ml}$ of iodomethane. The contents were mixed for 30 minutes using tube rotor, centrifuged for 5 minutes and upper layer was saved for counting. The lower layer was dried under a stream of nitrogen at $37^{\circ} \mathrm{C}$. The dried material was supposedly composed of methyl esters of mycolic acids and other fatty acids.

\section{Detection of mycolates by unidimensional TLC}

The mycolate fraction was dissolved in a small volume of petroleum ether (b.p. $40-60^{\circ} \mathrm{C}$ ) and spotted on a $10 \times 10$ silica gel G-precoated aluminium plate and developed with petroleum ether: diethyl ether (90:10) five times followed by $100 \%$ methanol once. The plate was sprayed with $0.5 \%$ potassium dichromate in $10 \%$ sulphuric acid and heated at $120^{\circ} \mathrm{C}$ for $10 \mathrm{~min}$. The mycolates were identified using standard mycolates from M. tuberculosis and the spots on the TLC plates were scrapped and collected in scintillation vial. $10 \mathrm{ml}$ of scintillation fluid was added and the radioactive counts were read by Liquid Scintillation Counter (Rackbeta-LKB, Wallac). The radioactivity in cell free-Sauton's medium and the supernatants saved at every stage of experiment was measured by diluting a suitable aliquot with scintillation fluid and counting in a Liquid Scintillation Counter.

\section{Computation of radioactivity into various lipid fractions}

The percent incorporations of the radioactive 1- $\mathrm{C}^{14}$-palmitic acid, 1-C ${ }^{14}$-sodium-n-valerate, 1-C ${ }^{14}$-sodium-n-acetate and $1-\mathrm{C}^{14}$-sodium-n- propionate into phenolic glycolipids, wax ester (PDIMs) and mycolates were calculated from the counts per minute (cpm) of the individual lipid fractions and the total counts and radioactivity incorporated into each lipid fraction was expressed as percent of the total radioactivity assimilated.

\section{Results}

\section{Incorporation of labeled 1- $\mathrm{C}^{14}$-palmitic acid into lipid of $\mathrm{M}$} .bovis BCG and $M$. kansasii

Significant radioactivity has been found in phenolic glycolipids (PGL), wax esters (PDIMs) and mycolates of $M$. bovis $\mathrm{BCG}$ and $M$. kansasii incubated into $1-\mathrm{C}^{14}$-palmitic acid $(2 \mu \mathrm{Ci}$, specific activity $23.3 \mathrm{mCi} / \mathrm{mmol})$. The counts per minute ranged from 3950 in case of PGL to 14000 for mycolates through a count of 8400 in wax esters, in the case of $M$. bovis BCG while the radioactivity as per cpm in case of $M$. kansasii phenolic glycolipids, wax esters and mycolate fractions were 4872,8872 and 11543 respectively. The percentage of total radioactivity assimilated into lipids of $M$. bovis BCG was: PGL: $0.39 \%$, PDIM: $0.70 \%$ and Mycolates: $0.30 \%$. In M. kansasii the values were: PGL: $0.42 \%$, PDIM: $0.81 \%$ and Mycolates: $1.45 \%$. (Table 1, Figure 1). The incorporation, when expressed as percentage of total radioactivity, ranged from $0.39 \%$ to $1.45 \%$.

\section{Incorporation of labeled 1-C ${ }^{14}$-valerate into lipids of $M$. bovis BCG and M.kansasii}

Significant radioactivity has been found in phenolic glycolipids (PGL), wax esters (PDIMs) and mycolates of $M$. bovis $\mathrm{BCG}$ and $M$. kansasii incubated into $1-\mathrm{C}^{14}$-sodium $\mathrm{n}$-valerate $(1 \mu \mathrm{Ci} / \mathrm{ml}$, specific activity $10.14 \mathrm{mCi} / \mathrm{mmol})$. The counts 
per minute ranged from 3600 in case of PGL to 12010 for mycolates through a count of 6600 in wax esters, in the case of $M$. bovis BCG while the radioactivity incorporated as per cpm in the case of $M$. kansasii Phenolic Glycolipids, wax esters and mycolate fractions were 3800,6600 and 11543 respectively. The percentage of assimilation of $1{ }^{14} \mathrm{C}$ - sodium-n-valerate into lipids of $M$. bovis BCG as; PGL: 0.28\%, PDIM: 0.58\% and Mycolates: $1.05 \%$. In M. kansasii the values were: PGL: $0.35 \%$, PDIM: $0.68 \%$ and Mycolates:0.90\% (Table:1, Figure. 1 ). The incorporation, when expressed as percentage of total radioactivity, ranged from $0.28 \%$ to 1.05 $\%$.

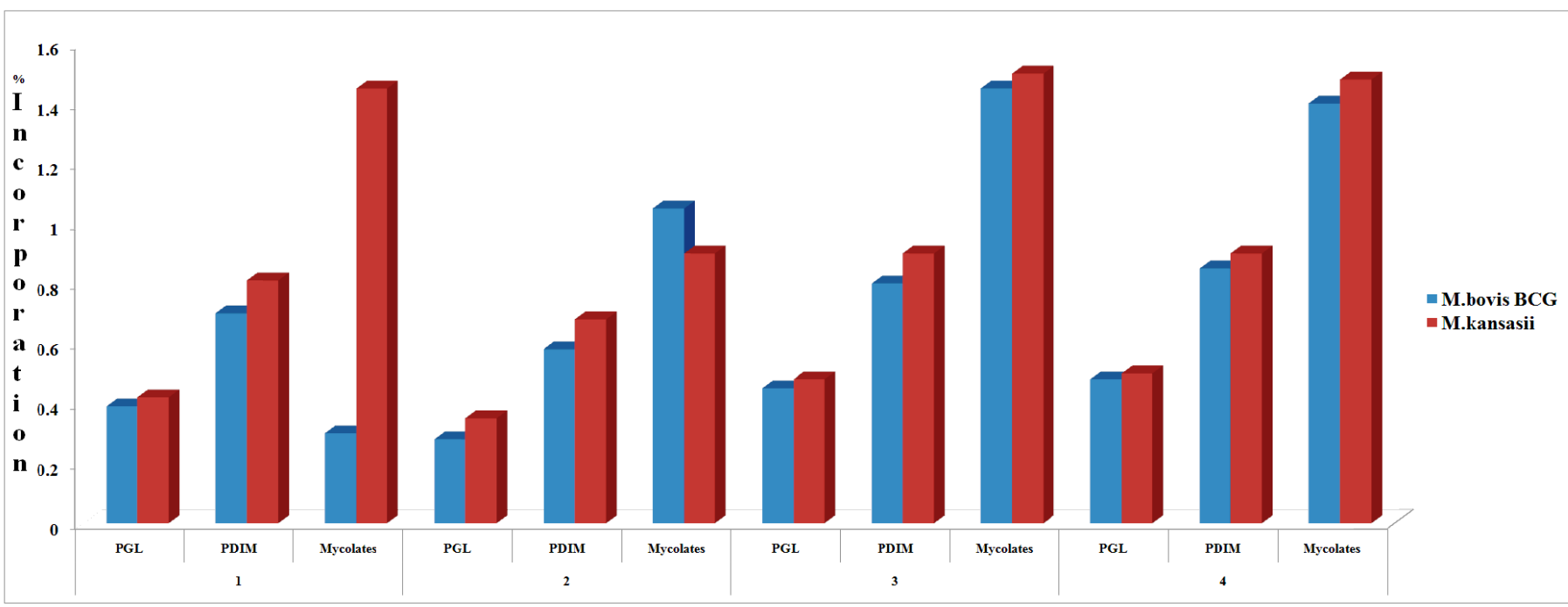

Figure 1: Incorporation of radioactivie labeled 1- $\mathrm{C}^{14}$-palmitate, 1- $\mathrm{C}^{14}$-valerate, $1-\mathrm{C}^{14}$-acetate and 1- $\mathrm{C}^{14}$-propionate into cell wall lipids of $M$. bovis BCG and $M$. kansasii.
1: $1-C^{14}$-palmitate
2: $1-\mathrm{C}^{14}$-valerate
3: $1-\mathrm{C}^{14}$-acetate
4: $1-\mathrm{C}^{14}$-propionate

Table1: Incorporation of 1-C ${ }^{14}$ labeled substrates into cell wall lipids of $M$. bovis $\mathrm{BCG}$ and $M$. kansaii.

\begin{tabular}{|c|c|c|c|}
\hline Radio labelled substrate & Lipid Fractions & M. bovis $\mathrm{BCG}$ & M. kansasii \\
\hline \multirow{3}{*}{ 1-C $C^{14}$-palmitic acid } & PGL & 0.39 & 0.42 \\
\hline & PDIM & 0.70 & 0.81 \\
\hline & Mycolates & 0.30 & 1.45 \\
\hline \multirow{3}{*}{ 1-C $C^{14}$-sodium-n-valerate } & PGL & 0.28 & 0.35 \\
\hline & PDIM & 0.58 & 0.68 \\
\hline & Mycolates & 1.05 & 0.90 \\
\hline \multirow{3}{*}{ 1-C ${ }^{14}$-sodium n-acetate } & PGL & 0.45 & 0.48 \\
\hline & PDIM & 0.80 & 0.90 \\
\hline & Mycolates & 1.45 & 1.50 \\
\hline \multirow{3}{*}{ 1-C $C^{14}$-sodium-n-propionate } & PGL & 0.48 & 0.50 \\
\hline & PDIM & 0.85 & 0.90 \\
\hline & Mycolates & 1.40 & 1.48 \\
\hline
\end{tabular}

Incorporation of labeled 1- $\mathrm{C}^{14}$-acetate into lipids of $M$. bovis BCG and $M$. kansasii

Significant radioactivity has been found in phenolic glycolipids (PGL), wax esters (PDIMs) and mycolates of M.bovis $\mathrm{BCG}$ and $M$. kansasii incubated into $1-\mathrm{C}^{14}$-sodium n-acetate $(2 \mu \mathrm{Ci} / \mathrm{ml}$, specific activity $40 \mathrm{mCi} / \mathrm{mmol})$. The percentage of assimilation of $1{ }^{14} \mathrm{C}$ - sodium-n- acetate into lipids of $M$. bovis BCG was: PGL: $0.45 \%$, PDIM: $0.80 \%$ and Mycolates: $1.45 \%$. In M. kansasii the values were: PGL: $0.48 \%$, PDIM: $0.90 \%$ and Mycolates: $1.50 \%$ (Table: 1, Figure.1). The incorporation, when expressed as percentage of total radioactivity, ranged from 0.45 $\%$ to $1.50 \%$.
Incorporation of labeled $1-C^{14}$-propionate into lipids of $M$. bovis BCG and $M$. kansasii

Significant radioactivity has been found in Phenolic Glycolipids (PGL), wax esters (PDIMs) and mycolates of $M$. bovis $\mathrm{BCG}$ and $M$. kansasii incubated into $1-\mathrm{C}^{14}$-sodium n-propionate $(2 \mu \mathrm{Ci} / \mathrm{ml}$, specific activity $5-20 \mathrm{mCi} / \mathrm{mmol})$. The percentage of assimilation of $1{ }^{14} \mathrm{C}$ - sodium-n-propionate into lipids of $M$. bovis BCG was: PGL: 0.48\%, PDIM: 0.85\% and Mycolates: $1.40 \%$. In $M$. kansasii the values were: PGL: $0.50 \%$, PDIM: $0.90 \%$ and Mycolates: $1.48 \%$.(Table:1, Figure.1). The incorporation, when expressed as percentage of total radioactivity, ranged from $0.48 \%$ to $1.48 \%$. 


\section{Discussion}

Lipid profiles of mycobacteria have been increasingly used in the chemotaxonomy of mycobacteria ${ }^{[7]}$. Phthiocerol Dimycocerosates (PDIMs) are proving to be powerful characters for the classification and identification of a limited number of mycobacteria. It is present only in very limited number of mycobacterial species like M.tuberculosis, M. bovis, M. marinum, M. microti, M. kansasii and M. leprae ${ }^{[3,8]}$. M. bovis has shown dimycocerosates of all three members of phthiocerol family, viz., phthiocerol A, phthiocerol B and phthiodiolone A. The phthiocerol A derived ester is the major constituent in both $M$. bovis and $M$. tuberculosis strains. Therefore, in species identification, PDIM can give supportive role to phenolic glycolipids and mycolates.

Incorporation of labeled substrates like acetate, propionate, palmitate into various mycobacterial cell wall lipid fractions has been studied. These include the studies on biosynthesis of lipids, development of sensitive tools for antimicrobial screening etc. There is limited information on the biosynthesis of phenolic glycolipids and their components ${ }^{[9-11]}$. The carbon atoms in the methyl branched structure in mycocerosic acids has been shown to be derived from propionate ${ }^{[12,13]}$. Phenolphthiocerol dimycocerosates were identified as the intermediates in the biosynthesis of phenolic glycolipids ${ }^{[11]}$. Two steps in the biosynthesis of mycocerosic acid have been demonstrated and the enzymes isolated by Rainwater and Kolattukudy ${ }^{[14-16]}$ the biosynthetic steps leading to phenolphthiocerol itself are not known. In vitro biosynthesis of PGL-I from 1- $\mathrm{C}^{14}$-acetate by $M$. leprae within Schwannoma cell lines has been reported by Mukherjee et $a l^{[17]}$. Incorporation of $\left[\mathrm{U}_{-}{ }^{14} \mathrm{C}\right]$ palmitic acid into phenolic lipid-I (PGL-I) fraction of $M$. leprae in murine macrophage system in vitro was found useful in quantitating the metabolism of $M$. leprae in macrophages Ramasesh et a $l^{[18]}$. These workers reported that the percent incorporation of labeled palmitic acid into PGL-I depended on experimental condition but did not exceed $1 \%$ (range 0.4 to $0.6 \%$ ). It has also been reported by them that treatment of infected macrophages with rifampicin caused a significant reduction in the incorporation of $1-\mathrm{C}^{14}$-palmitic acid into PGL-I fraction. In our study we have found that the percent incorporation of labeled 1-C ${ }^{14}$-palmitic acid , 1-C $\mathrm{C}^{14}$-valerate, 1-C $\mathrm{C}^{14}$-acetate and 1-C $\mathrm{C}^{14}$-propionate into phenolic glycolipids in $M$. bovis BCG and M. kansasii ranged from $0.28 \%$ to $0.50 \%$. The incorporation of labeled PGL was least in 1-C $\mathrm{C}^{14}$-valerate of M. bovis BCG and highest in 1-C $\mathrm{C}^{14}$-propionate of M. kansasii. The percent incorporation into wax esters fraction ranged from ters) was least in 1-C $\mathrm{C}^{14}$-valerate of M.bovis BCG and highest in 1-C $\mathrm{C}^{14}$-propionate of $M$. kansasii. The percent incorporation into mycolate fraction ranged from 0.30 to $1.50 \%$. The incorporation of mycolate was least in 1-C $\mathrm{C}^{14}$-palmitic acid of $M$. bovis BCG and highest in $1-\mathrm{C}^{14}$-acetate of $M$. kansasii.

The findings of the present study suggest that uptake of radiolabeled substrates like $1-\mathrm{C}^{14}$-palmitic acid, $1-\mathrm{C}^{14}$-valerate, $1-\mathrm{C}^{14}$-acetate and $1-\mathrm{C}^{14}$-propionate and their incorporation into various cell wall lipids will be helpful in studies on viability, lipid biosynthesis and screening of antimicrobials. 0.58 to $0.90 \%$. The incorporation of labeled PDIM (wax es-

\section{Conclusion}

The incorporation of radiolabelled substrates like 1-C $\mathrm{C}^{14}$-palmitate, 1-C $\mathrm{C}^{14}$-valerate, 1-C $\mathrm{C}^{14}$-acetate and 1-C $\mathrm{C}^{14}$-propionate into PGLs, PDIMs and mycolates was adequate in $M$. bovis BCG and M. kansasii. The incorporation of radioactivity into specific lipid fraction as a percentage of total radioactivity assimilated varied from $0.28 \%$ in the case of PGL to $1.5 \%$ in mycolates. This study suggests the usefulness of radiolabelled substrate incorporation approach in determining the viability of the bacilli, probe into biosynthesis of lipids and screening chemotherapeutic agents for their antimyobacterial efficacy.

Conflict of interest: There is no conflict of interest among the authors.

Acknowledgements: The authors are grateful to Director, NJIL \& OMD for the support. The research was supported by ICMR, New Delhi. Authors are also thankful to Dr. Pradeep Dagur, Mr. Neeraj Dubey, Mr. Vijay Dua and staff of Biochemistry Division.

\section{References:}

1. Board, R.G., Goodfellow M. Microbiological classification and identification. (1980) Academic Press, London 184-256.

2. Ratledge, C., Stanford, J.L. The Biology of Mycobacteria. (1982) Academic Press, London (1): 95-184.

3. Dobson, G., Minnikin, D.E., Minnikin, S.M., et al. 'Chemical methods in bacterial systemics' (Goodfellow, M. and Minnikin, D.E., eds.) (1985) Academic Press, London 237-265.

4. Randall, H.M., Smith, D.W. Characterization of mycobacteria by infrared spectroscopic examination of their lipid fractions. Zentrablatt fur Bakteriologie, Parasitenkunde, Infektionskrankheiten und Hygiene. (1964) I. Abteilung. 194: 190-201.

5. Draper, P., Payne, S., Dobson, G., et al. Isolation of a characteristic phthiocerol dimycocerosate from Mycobacterium leprae. (1983) J Gen Microbiol 129(2): 859-863.

Pubmed I Crossref

6. Goren, M.B., Brokl, O., Schaefer, W.B., Lipids of putative relevance to virulence in Mycobacterium tuberculosis: Phthiocerol dimycocerosate and the attenuation indicator lipid. (1974) Infect Immun 9(1): 150-158.

Pubmed

7. Minnikin, D.E., Lipids, their chemistry, biosynthesis and roles. "The Biology of Mycobacteria"Ratledge C and Stanford J. (1982) London Academic Press 95-184.

8. Dandapat, P., Verma, R., Venkatesan, K., et al. Rapid detection of Mycobacterium bovis on its lipid profile by thin layer chromatography. (1999) Vet Microbiol 65(2): 145-151.

Pubmed I Crossref

9. Gastembide-Odier, M., Sarda, P. Contribution a l'etude de la structure et de la biosynthese de glycolipides specifiques isoles de mycobacteries, les mycosides A\& B. (1970) Pneumonology 142(2): 241-255.

Pubmed I Crossref

10. Thurman, P., Draper, P. Biosynthesis of Phenolic glycolipids in M.microtii. (1989) Acta Leprologica 7 (Suppl 1): 74-76.

Pubmed

11. Thurman, P., Chai, W., Rosankiewicz, J.R., et al. Possible intermediates in the biosynthesis of mycoside $\mathrm{B}$ by Mycobacterium microtii. (1993) Eur J Biochem 212(3): 705-711.

Pubmed

12. Gastambide-Odier, M., Delaumeny, J.M., Lederer E. Biosynthese de l'acide C32-mycocerosique: incorporation d'acide propionique. 
(1963) Biochem Biophys Acta 70: 670-678.

Pubmed I Crossref

13. Yano, I., Kusunose, M. Propionate incorporion into mycocerosic acid by resting cells of Mycobacterium tuberculosis bovis. (1966) Biochim Biophys Acta 116(3): 593-596.

Pubmed I Crossref

14. Rainwater, D.L., Kolattukudy PE. Isolation and characterization of acyl coenzyme A carboxylase from Mycobacterium tuberculosis and Mycobacterium bovis which produce multiple methyl branched mycocerosic acids. (1982) J Bacteriol 151(2): 905-911.

Pubmed I Crossref

15. Rainwater, D.L., Kolattukudy, P.E. Synthesis of mycocerosic acids from methylmalonyl A coenzyme by cell-free extracts of Mycobacterium tuberculosis var bovis BCG. (1983) J Biol Chem 258(5): 2979 2985.

Pubmed I Crossref

16. Rainwater, D.L., Kolattukudy, P.E. Fatty acid synthesis in Mycobacterium tuberculosis var bovis Bacillus Calmette-Guerin. Purification and characterization of a novel fatty acid synthase, mycocerosic acid synthase, which elongates n-fatty acyl-CoA with methylmalonyl-CoA. (1985) J Biol Chem 260(1): 616-623.

Pubmed I Crossref

17. Mukherjee, R., Mistry, V., Antia, N.H., et al. Incorporation of $14 \mathrm{C}$ acetate into specific phenolic glycolipid of M. leprae, maintained within cultured cells. (1985) IRCS Med Sci 13: 203-204.

18. Ramashesh, N., Hastings, R.C., Krahenbuhl, J.L. Metabolism of Mycobacterium leprae in macrophages. (1987) Infect Immun 55(5): 1203-1206.

Pubmed 